\title{
nominata de pareceristas
}

\begin{tabular}{|c|c|c|}
\hline $\begin{array}{l}\text { Nome } \\
\text { Acácio de Camargo Piedade } \\
\text { Airton Jungblut } \\
\text { Amnéris Maroni } \\
\text { Ana Claudia Rocha Marques } \\
\text { nna Paula Cavalcanti Simioni } \\
\text { Ana Paula de Oliveira } \\
\text { Andréa Ciacchi } \\
\text { Antonella Tassinari } \\
\text { Arsênio Oswaldo Seva Filho } \\
\text { Berenice Alvez de Melo Bento } \\
\text { Bianca Freire Medeiros } \\
\text {-arlos Guilherme Valle } \\
\text {-armem Rial } \\
\text {-ecília Mariz } \\
\text {-elso Castro } \\
\text {-hristine de Alencar Chaves } \\
\text {-ornélia Eckert } \\
\text { ristina Bruno } \\
\text { ébora Krischke Leitão } \\
\text { Edgar Malagodi } \\
\text { liane Tânia Martins de Freitas } \\
\text {-abiano Gontijo } \\
\text {-ernanda Peixoto } \\
\text {-ernando Pinherio } \\
\text {-rancisco Silva Neto } \\
\text { Gilberto Velho } \\
\text { oão Cruz } \\
\text { ohn Comerford } \\
\text { ohn Cowart Dawsey } \\
\text { ohn Monteiro } \\
\text { osé Carlos Souza Rodrigues }\end{array}$ & $\begin{array}{l}\text { Filiação institucion } \\
\text { (UDESC) } \\
\text { (PUC- RS) } \\
\text { (UNICAMP) } \\
\text { (USP) } \\
\text { (USP) } \\
\text { (UFFF) } \\
\text { (UFPB) } \\
\text { (UFSC) } \\
\text { (UNICAMP) } \\
\text { (UnB) } \\
\text { (CPDOC/FGV-RJ) } \\
\text { (UFRN) } \\
\text { (UFSC) } \\
\text { (UERJ) } \\
\text { (FGV) } \\
\text { (UFPR) } \\
\text { (UFRGS) } \\
\text { (USP) } \\
\text { (UEL) } \\
\text { (UFCG) } \\
\text { (UFRN) } \\
\text { (UFPI) } \\
\text { (USP) } \\
\text { (USP) } \\
\text { (UFJF) } \\
\text { (MN/UFRJ) } \\
\text { (UnB) } \\
\text { (UFRRJ) } \\
\text { (USP) } \\
\text { (UNICAMP) } \\
\text { (PUC-RJ/ SCM/RJ) } \\
\text { (UNIFESP/USP) } \\
\text { (USP) } \\
\text { (CEBRAP/PUC- RJ) } \\
\text { - } \\
\text { (UFRN) } \\
\text { (USP) } \\
\text { (USP) } \\
\text { (UFG) } \\
\text { (USP) } \\
\text { (UFSM) } \\
\text { (CEBRAP) } \\
\text { (MN/UFR) } \\
\text { (UNIFESP) } \\
\text { (UFPE) } \\
\text { (Mackenzie) } \\
\text { (UFRGS) } \\
\text { (FIOCRUZ/UFAM) } \\
\text { (UNICAMP) } \\
\text { (USP) } \\
\text { (CEBRAP/USP) } \\
\text { (UFSC) } \\
\text { (UERJ) } \\
\text { (UFV) } \\
\text { (UNIFESP) } \\
\text { (UFPE) } \\
\text { (UNICAMP) } \\
\text { (UNIP) } \\
\text { (UFPR) } \\
\text { (PUC-RJ / UCAM) } \\
\text { (UFPR) } \\
\text { (UFMA) } \\
\text { (UFSC) } \\
\text { (UnB) } \\
\text { (UFSC) } \\
\text { (UFS) }\end{array}$ & 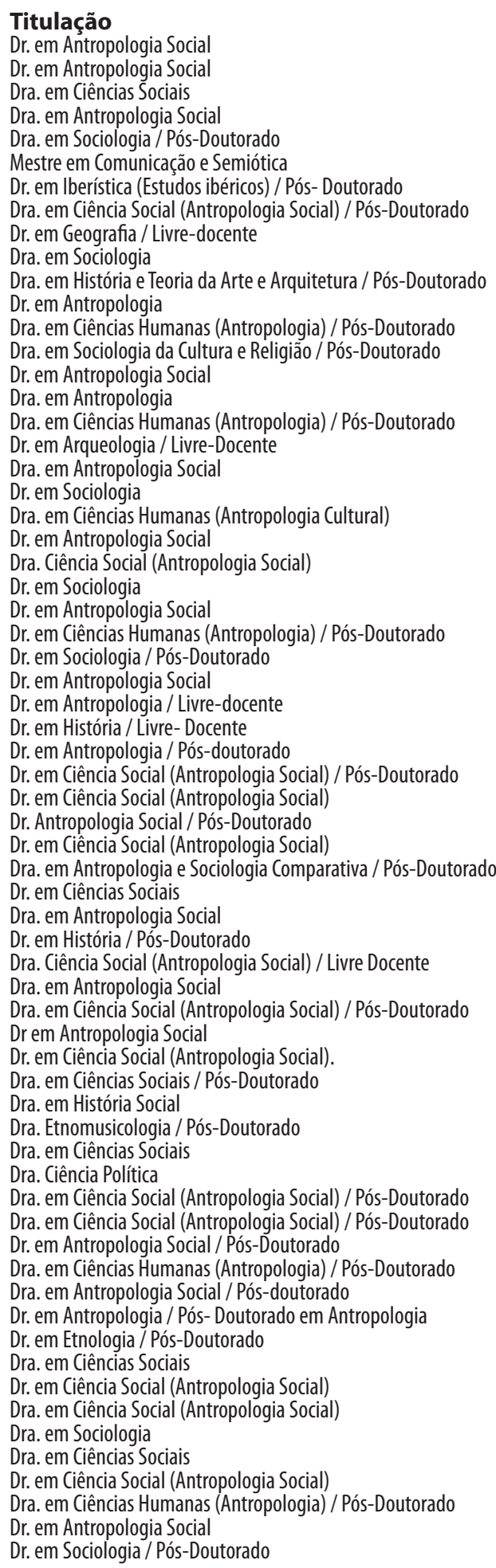 \\
\hline
\end{tabular}

cadernos de campo, São Paulo, n. 16, p. 1-304, 2007 